\title{
Dynamic Simulation and Experiments of a Novel Variable Valve Timing System
}

\author{
Chen Jia-dui \\ College of Mechanical Engineering of Guizhou University \\ chjd97@163.com
}

\begin{abstract}
A principle of best engine valve timing is proposed based on the requirements of best engine valve timing. A novel variable valve timing system is edesigned according to the principle. The construction of the mathematical model of the system and its dynamic simulation are also presented. The adjust performance of system and the oil pressure are studied in the paper. Simulation and experimental results shout that the system can achieve fully variable valve timing adjustment by regulating electromaghetic valve closing time according to the engine speed, and the system satisfies the principle of best engine valve timing proposed in the paper.
\end{abstract}

Keywords: variable valve timing, the principle of best yalve timing, mathematical model, simulation, oil pressure

\section{Introduction}

VVT technology can inpprove the idle speed stability, the low speed stability, the emissions, the power and economick of the engine [1], so VVT technology has been recognized by the society and many automobile enterprises have paid attention to it. Many automobile enterprises and scientific research institutions have carried out research on it, achieving a great deal of results [2-8]. So far, there is a lot of commercial VVT technology. Toyota's VVT-1,BMW's Vanos, Ford's VCT, Delphi's VCP, Nissan's CVVT, Hyundai's VVT, Kia's CVVT and 80 on are the typical representative. The principle of these VVT systems is the camshaftchase modulation that the adjustment of valve timing through the change of the relative phase of the cam shaft and crankshaft. This method can realizes continuously adjust of the valve timing in a certain angle range. Compared with traditional valve system, it can greatly improve the performance of the engine. Due to the fatal flaw that the cam profile is immutable, the valve duration angle of these VVT systems can not be changed. It can only achieve the adjusting effect that the valve advance angle is good, but the valve lag angle is bad, or the valve lag angle is good, but the valve advance angle is bad. It makes the engine can not get the best valve timing in each condition but the condition was considered in the design of cam profile. It also leads to the limited effect of engine performance and the energy-saving.

The system such as Honda's VTEC (Variable Valve Timing and Valve Life Electronic Control System), Porsche's Vario-Cam and Audi's AVS, which adopts multi cam to adjust valve timing and lift can only achieve the best adjustment of valve timing and lift control in several engine speeds or load [9], but can't achieve the best valve timing in all working conditions.

The Fiat's 3D cam continuously variable valve timing mechanism can achieve continuous adjustment of valve timing, duration angle and lift in a certain range [1]. Due to the serious 
wear which caused by the point contact between the cam and follower, at the same time, the complex structure and high cost, the mechanism fails to achieve widespread application.

Due to existing VVT technologies have defects, a principle of best valve timing is proposed based on the study of optimal engine valve timing requirements. A novel variable valve timing system is designed according to it. And the system is studied by simulation and experiment.

\section{Analysis of the Best Engine Valve Timing Requirements}

The best engine valve timing is that the engine has the most appropriate valve timing in each working condition, to make the power, the economy and the emission performance of engine has the good performance.

The intake air velocity is very high and the flow inertia is great when the engine, running at high speeds [11]. In this case, increasing the intake valve advance anglercan guarantee fresh gas or combustible mixture gas smoothly and fully into the cylinder. Increasing intake valve late closed angle can take advantage of the inertia of the intake air flow to enhance the charging amount of cylinder in order to improve the engine performance. Meanwhile, in order to exhaust the gas of cylinder as much as possible, the-exhaust valve/advance angle should be increased, using the good power stroke that fronc cylinder pressure is greater than the pressure of outside cylinder to exhaust in advance. While increasing the exhaust valve lag angle can make full use of the inertia of exhaust and the effect of intake to exhaust more gas out of cylinder. The overlap angle of intake walve and exhaust valve is greatly increased, so intake efficiency is improved and engine pefformance is enhanced.

The intake air velocity is low and the flow inertia is small when the engine running at low speeds or idle. In this case, if the intake valve opens prematurely, while the piston is still in the upward exhaust, the freshair will be extruded from the cylinder, some exhaust gas will go into the intake manifold. All of these will result in reducing the amount of intake air and making the work of engine unstable. However, if the open time of intake valve is delayed, that is the intake valve is opened yhen the piston has a very small downlink speed and the opening of intake valve is small, the intake velocity will be increased, intake swirl also will be enhanced, so the mixed gas will obtain better homogeneity, higher combustion rate, more sufficient combustion and higher cycle efficiency. Thus, the intake valve advance angle should be decreased when the engine running at low speeds or idle. On the other hand, due to less mixed gas is needed when the engine running at low speeds or idle, the intake valve lag angle should be decreased to reduce the amount of intake air. In order to take full advantage of the work or gas, the exhaust valve advance angle should be decreased when the engine running at low speeds or idle. Meanwhile, in order to avoid the mixed gas outflow out of the cylinder from exhaust valve and excessive exhaust gas enter intake manifold to affect the amount of intake air, the exhaust valve lag angle and the overlap angle of intake valve and exhaust valve should be decreased.

In summary, the valve advance angle, the valve lag angle and the valve duration angle of the engine's intake and exhaust valves should be increased with the engine speed increasing, at the same time, it should decreased with the engine speed. This is the principle of best valve timing, as shown in Figure 1. That is the fatal flaw of VVT system which adopts the camshaft phase modulation principle. 


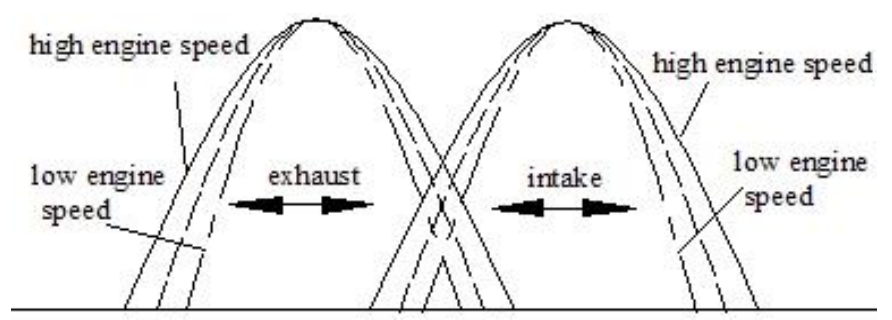

Figure 1. Schematic Diagram of the Principle of Best Engine Valve Timing

\section{Novel Variable Valve Timing System and Mathematical Modeling ${ }^{\bullet}$}

\subsection{Novel Variable Valve Timing System}

Figure 2 is the schematic diagram of hydraulic VVT systern. The system consists of cam, cam cylinder, valve cylinder, valve assembly, oil filling system and oil drain system. The oil filling system which consists of oil tank, oil pump, check vave, overflow valve and pipeline, provides the $0.2 \mathrm{MPa}-0.3 \mathrm{MPa}$ oil for the VVT system. The oil drain system consists of electromagnetic valve, oil tank, check valve and pipeline. The hydraulic system is supplied by cam. The reciprocating motion of cam piston is driven by the rotary of cam. When it is in the lift, the cam tappet moves right. The oil of system is drivento the right, and the oil pressure generates at the same time. When the force or oil acts on the valve piston is greater than the sum of valve spring's pre-tightening force and the friction force between the valve piston and valve cylinder, the valve opens. White cam is in return, the valve falls back under the action of the valve spring. When the force of oil acts on the valve piston less than the sum of valve spring's pre-tightening force and the frictionforce between the valve piston and valve cylinder, the valve seats. The time and the volume of oil into the valve cylinder are controlled by controlling the on-off Aime of the electromagnetic valve in the system. The control signal of electromagnetic valye dépends on the cam angle signal. The set pressure value of outlet check valve is $0.22 \mathrm{MPa}$.

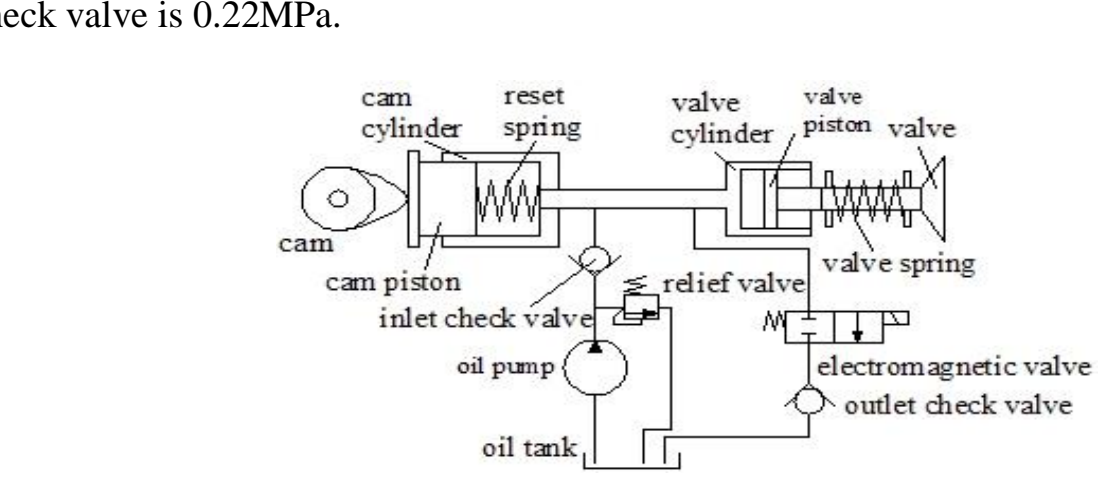

Figure 2. Schematic Diagram of Variable Valve Timing System

The work process of hydraulic VVT system: When the starting point of cam lift comes, the electromagnetic valve switches on. The oil that has been pumped out from the cam cylinder flows to the oil tank through the oil pump line. When cam comes to the angle of the valve needs to open, the electromagnetic valve closes. Then all of the oil that has been pumped out from the cam cylinder goes into the valve cylinder. When the force of oil acts on the valve piston is greater than the sum of valve spring's pre-tightening force and the friction force between the valve piston and valve cylinder, the valve opens and the opening of valve gradually increases until the end of cam lift. While cam in return, the valve falls back under 
the action of the valve spring. The oil flows back to the cam cylinder. The pressure of oil decreases at the same time. When the force of oil acts on the valve piston less than the sum of valve spring's pre-tightening force and the friction force between the valve piston and valve cylinder, the valve seats. If the oil pressure of system under the set value, the oil filling system would supply oil to keep the pressure.

From the working process of the system, the electromagnetic valve closing time affects the time of hydraulic oil flows into the valve cylinder, the volume and the time of hydraulic oil flows from it. The electromagnetic valve closes earlier, the time of hydraulic oil flows into the valve cylinder earlier, more hydraulic oil flows into the valve cylinder, and the time of hydraulic oil outflows from valve cylinder later, the valve advance angle, the valve lag angle and the valve duration angle larger. On the contrary, they are smaller. Therefore, the valve advance angle, the valve lag angle and the valve duration angle of valve can be adjusted by regulating electromagnetic valve closing time according to the engine speed. Furthermore, the system satisfies the principle of best engine valve timing proposed in the paper.

\subsection{Mathematical Modeling}

The mathematical model of system is established based on the structure and working principle of hydraulic VVT system. Its performances will be analyzed by mathematical modeling and simulating.

1) The displacement equation of cam piston

The cam piston is follower of cam. Its displacementis affiliated with the cam profile. The displacement equation of cam piston can be depicted as follows:

$$
x_{1}(\theta)= \begin{cases}3 \times\left[1-\cos \frac{\pi \times(\theta-30)}{140}\right], & \theta \in\left[30^{\circ}, 310^{\circ}\right] \\ 0 & \varepsilon^{140}+\left[30^{\circ}, 310^{\circ}\right]\end{cases}
$$

2) The continuous flow equation of cam cylinder

In consideration of compressibility flow, the continuous flow equation of cam cylinder is:

$$
A_{1} \frac{d x_{1}}{d t}-\frac{\nabla_{1}}{4 \beta} \frac{d p_{1}}{d t}-Q_{2}+Q_{3}-Q_{4}=0
$$

3) The continuous flow equation of valve cylinder

The cam cylinder and valve cylinder is connected with a slender tube. The continuous volume flow equation of hydraulic from the cam cylinder flow into the valve cylinder is [11]:

$$
Q_{2}=\frac{\pi d^{4}\left(p_{1}-p_{2}\right)}{128 \mu l}
$$

The continuous flow equation of valve cylinder can be divided into two cases, and they are expressed as follows.

a) When the force of oil acts on the valve piston less than the sum of valve spring's pretightening force and the friction force between the valve piston and valve cylinder, the valve can not move, the oil in the valve cylinder is compressed. In this case, the continuous flow equation of valve cylinder is:

$$
\frac{V_{2}}{4 \beta} \frac{d p_{2}}{d t}-Q_{2}=0
$$

b) when the force of oil acts on the valve piston is greater than the sum of valve spring's pre-tightening force and the friction force between the valve piston and valve cylinder, the valve moves. In this case, the continuous flow equation of valve cylinder is: 


$$
A_{2} \frac{d x_{2}}{d t}+\frac{V_{2}+x_{2} A_{2}}{4 \beta} \frac{d p_{2}}{d t}-Q_{2}=0
$$

4) The continuous flow equation of inlet check valve

Flow equation across the inlet check valve is expressed as:

$$
Q_{3}= \begin{cases}C_{d} A_{c 1} \sqrt{\frac{2 \times\left(p_{3}-p_{1}\right)}{\rho}} & p_{1}<p_{3} \\ 0 & p_{1}>p_{3}\end{cases}
$$

5) The continuous flow equation of electromagnetic valve

Flow equation across the electromagnetic valve is expressed as:

$$
Q_{4}= \begin{cases}C_{d} A_{c 2} \sqrt{\frac{2 \times\left(p_{1}-0.2\right)}{\rho}} & \text { electromagnetic valve open } \\ 0 & \end{cases}
$$

6) The equilibrium equation of the $v \varepsilon$

The valve assembly can be simplifie electromagnetic valye closed action of hydraulic force. The equilibrium equation of the valve exlinder piston is:

$$
A_{2} p_{2}-m_{2} \frac{d^{2} x_{2}}{d t^{2}}-c \frac{d x_{2}}{d t}-F_{2}-k_{2} x_{2}=0
$$

In this equation, $m_{2}$ is the equivalent quality of valyeassembly, can be expressed as:

$$
m_{2}=m_{p}+m_{v}+\frac{1}{3} m_{s}
$$

7) The relationship between the crank angle and engine speed at electromagnetic valve close time

$$
\alpha=f(n)
$$

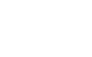

\section{The Simulation Model and Simulation Results}

The system is simulated by the dynamic graphical simulation software MATLAB/ SIMULINK. According to equation (1) (9), the simulation model is established. Figure 3 is the simulation model and the simulation parameters are shown in Table 1.

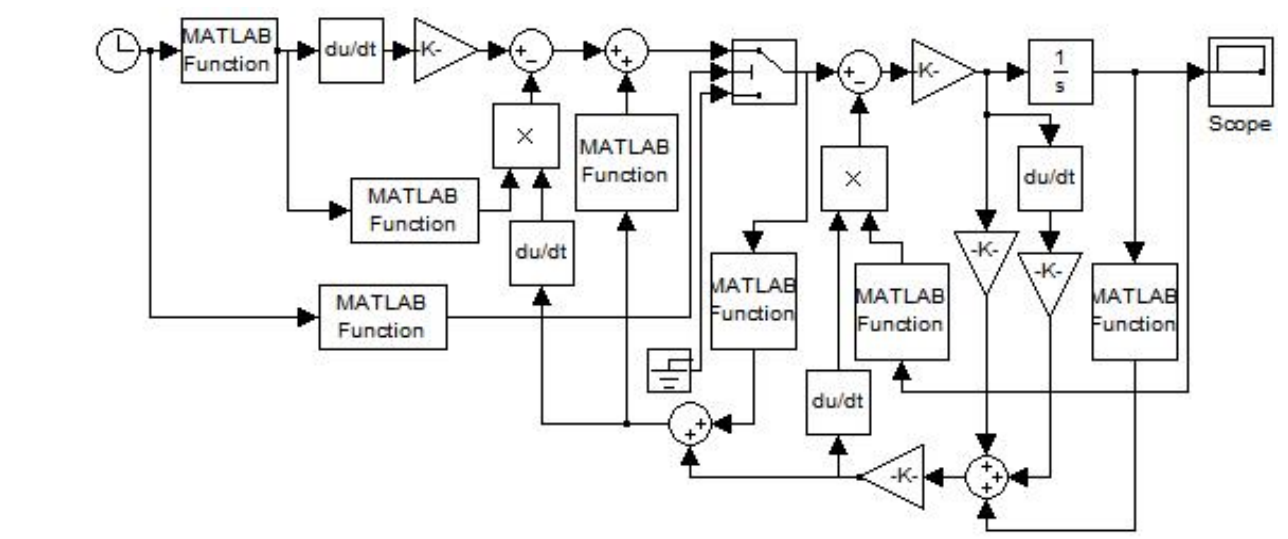

Figure 3. Simulation Block Diagram of System 
Table 1. Simulation Parameters of the Simulation Model

\begin{tabular}{|c|c|c|c|}
\hline$A_{1}\left(\mathrm{~mm}^{2}\right)$ & $A_{2}\left(\mathrm{~mm}^{2}\right)$ & $V_{01}\left(\mathrm{~mm}^{3}\right)$ & $V_{02}\left(\mathrm{~mm}^{3}\right)$ \\
\hline 201 & 100 & 2200 & 400 \\
\hline$\beta\left(\mathrm{mm}^{3} / \mathrm{Pa}\right)$ & $d(\mathrm{~mm})$ & $l(\mathrm{~mm})$ & $\mu\left(\mathrm{mm}^{2} / \mathrm{s}\right)$ \\
\hline 0.7 & 8 & 800 & 30 \\
\hline$C_{d}$ & $A_{C 1}\left(\mathrm{~mm}^{2}\right)$ & $\rho\left(\mathrm{Kg} / \mathrm{m}^{3}\right)$ & $m_{2}(\mathrm{Kg})$ \\
\hline 0.6 & 13 & 870 & 0.008 \\
\hline$C$ & $F_{02}(\mathrm{~N})$ & $k_{2}(\mathrm{~N} / \mathrm{mm})$ & $A_{C 2}\left(\mathrm{~mm}^{2}\right)$ \\
\hline 0.15 & 120 & 40 &
\end{tabular}

Figure 4 presents the simulation results of valve timing at different engine speed. Figure 4 shows the valve advance angle, the valve lag angle and the valve duration angle can be varied according to different engine speeds. Figure 5 shows the simulation results of valve timing at $3000 \mathrm{r} / \mathrm{min}$ and different electromagnetic valye closing time. The figure told that the valve advance angle, the valve lag angle and the valveduration angle can be adjusted at a certain engine speed. Figure 4 and figure 5also told that the valve timing adjustment affects the valve lift. The electromagnetie valye is closed earlier, the valve lift is greater. This result is required in the engine working. The largen valye lift is required at high engine speed, and small valve lift is required at loy engine speed.

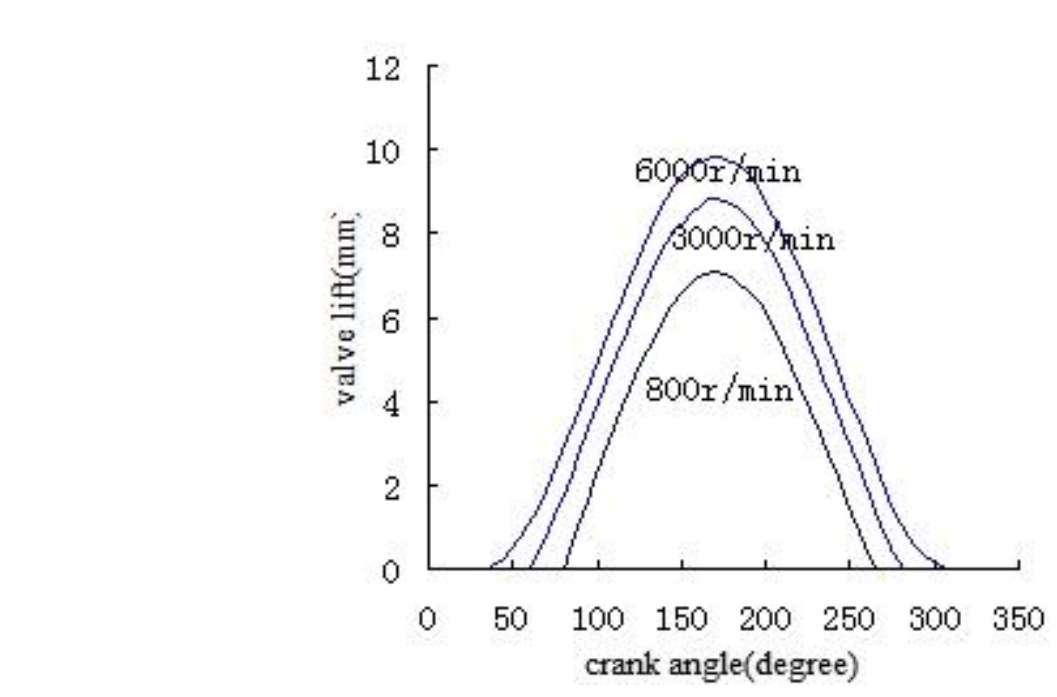

Figure 4. Simulation Results of Valve Timing at Different Engine Speed 


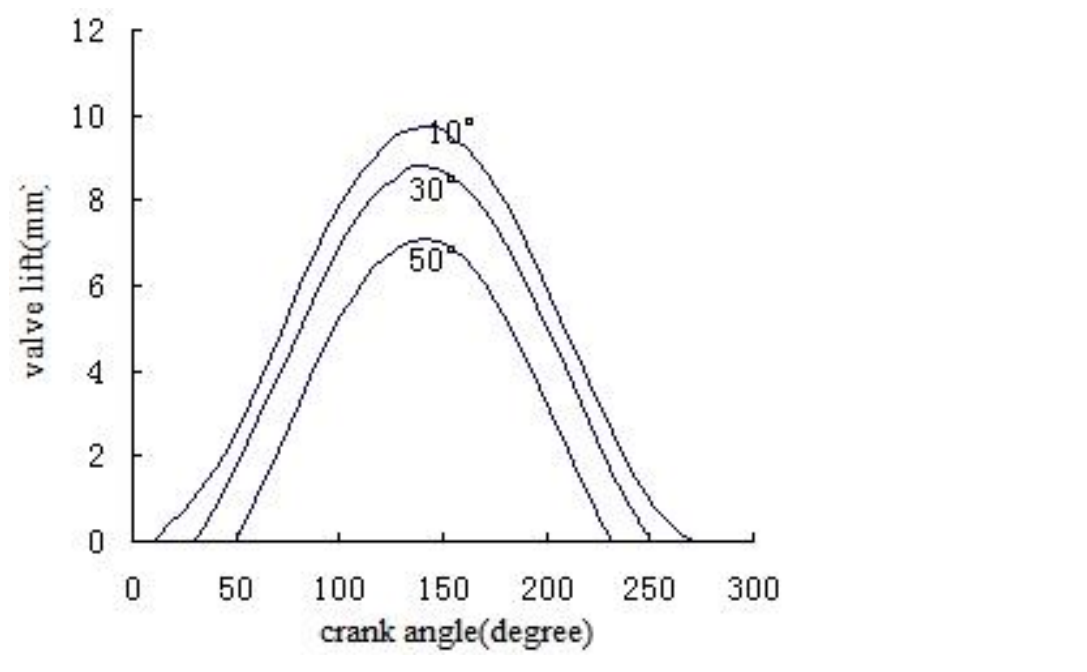

Figure 5. Simulation Results of Different Adjustment at $3000 \mathrm{r} / \mathrm{min}$

\section{Experiment and Results}

\subsection{Experiment Apparatus}

Test apparatus is shown in Figure 6. The servo rotor simulates the engine to provide power for the cam shaft. The different engine speed is to be simulated by the servo driver adjusts the rotating speed of servo motor. Servo motor, electromagnetic valve and the motor of oil pump are controlled by Programmable bogic Controller (PLC). The signals of No.1 phase sensor are processed by PLC and then used to control the on-off of the electromagnetic valve. Human Machine Inferface (HMI) is used to input the rotating speed of servo motor and human-computer interaction of other information of system.No.2 phase sensor is used to measure the phase of camshaft The real-time oil pressure of cam cylinder and valve cylinder is measured by two high frequency pressure sensor. Laser displacement sensor is used measured the real-time displacement of valve. All signals are collected and recorded by the data acquisition system, and are processed and analyzed by computer.

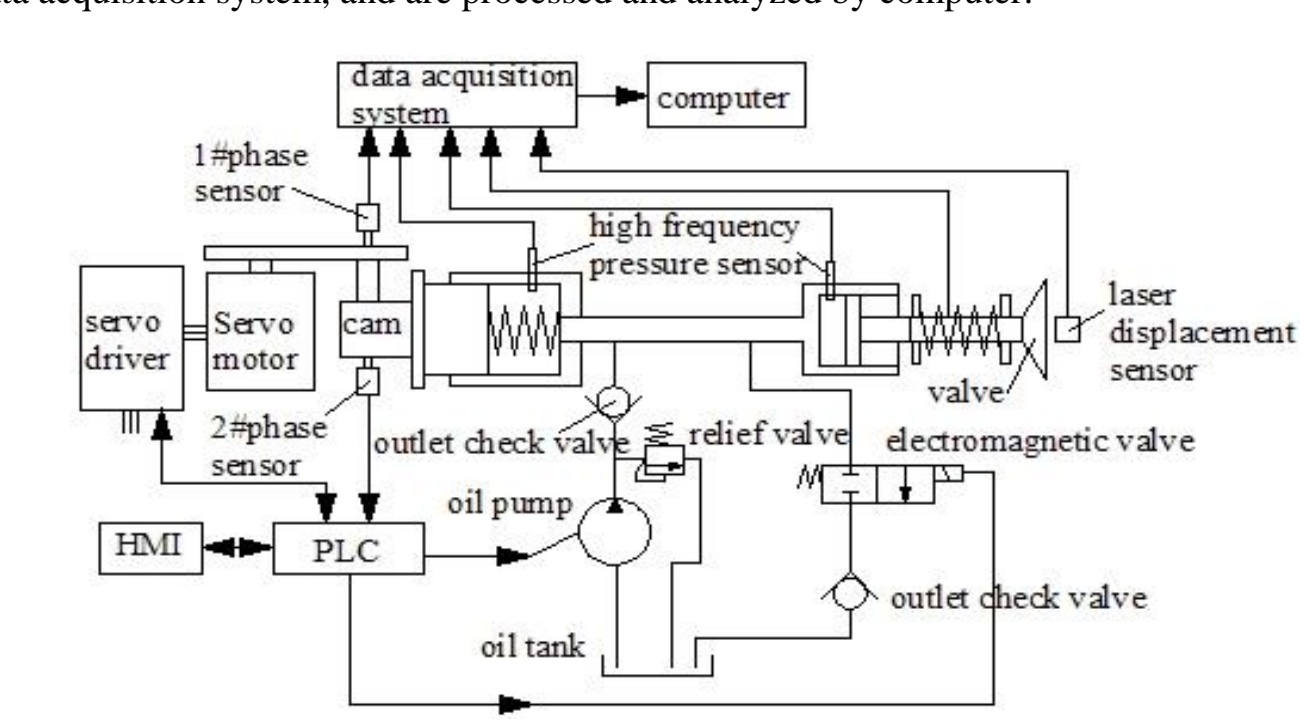

Figure 6. Test Apparatus Diagram 


\subsection{Experimental Results}

The opening and closing of electromagnetic valve belongs to process control. In order to make the experimental results consistent with the simulation results, the on-off time of electromagnetic valve in the experiment is slightly ahead of simulation parameter. Figure 7 shows the experimental results at valve timing adjustment test of different engine speed. Figure 8 shows the experimental results of electromagnetic valve different on-off time at $3000 \mathrm{r} / \mathrm{min}$.From two figures, it's known that there is some difference between the experimental results and simulation results, but the difference is very small. So, it can be said that the experimental results consistent with the simulation results. The result proves the validity of mathematical model. The errors between the experimental results and simulation results are caused by leakage of experimental system and error of hydraulic oil parameter.

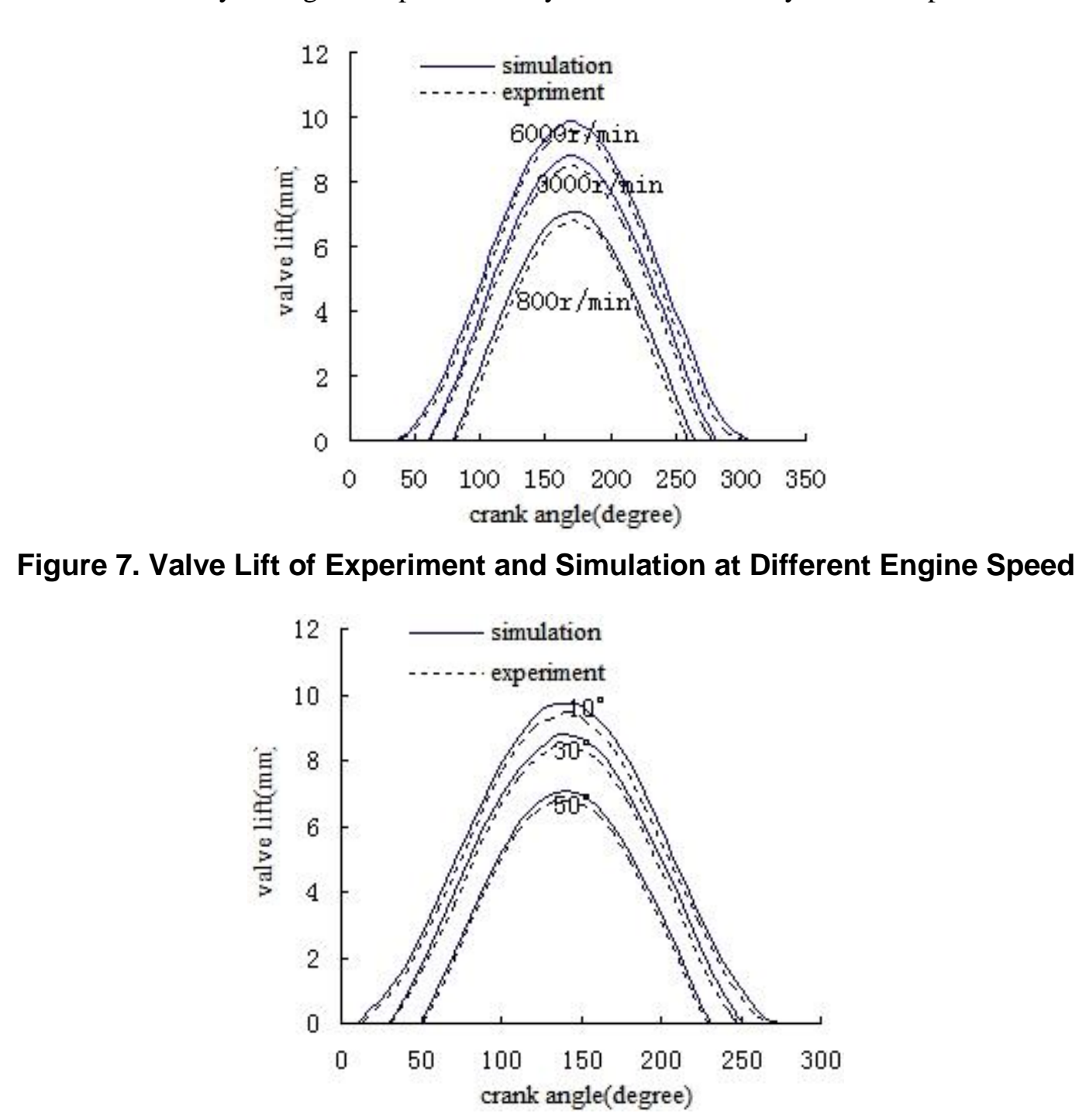

Figure 8. Valve Lift of Electromagnetic Valve Different on-off time at 3000r/min

Figure 9-- Figure 12 show the comparison of oil pressure of valve cylinder between experimental results and simulation results at different engine speeds. The Figures show that, with the increase of engine speed, the pressure of valve cylinder increases, and the pressure 
fluctuation is intensified. There is a situation that the instantaneous pressure of valve cylinder nearly closes to the pressure of oil filling system during the process of valve open at $6000 \mathrm{r} / \mathrm{min}$. If the engine speed over6000 $/ \mathrm{min}$, it will appear the phenomenon that the valve is out of control.

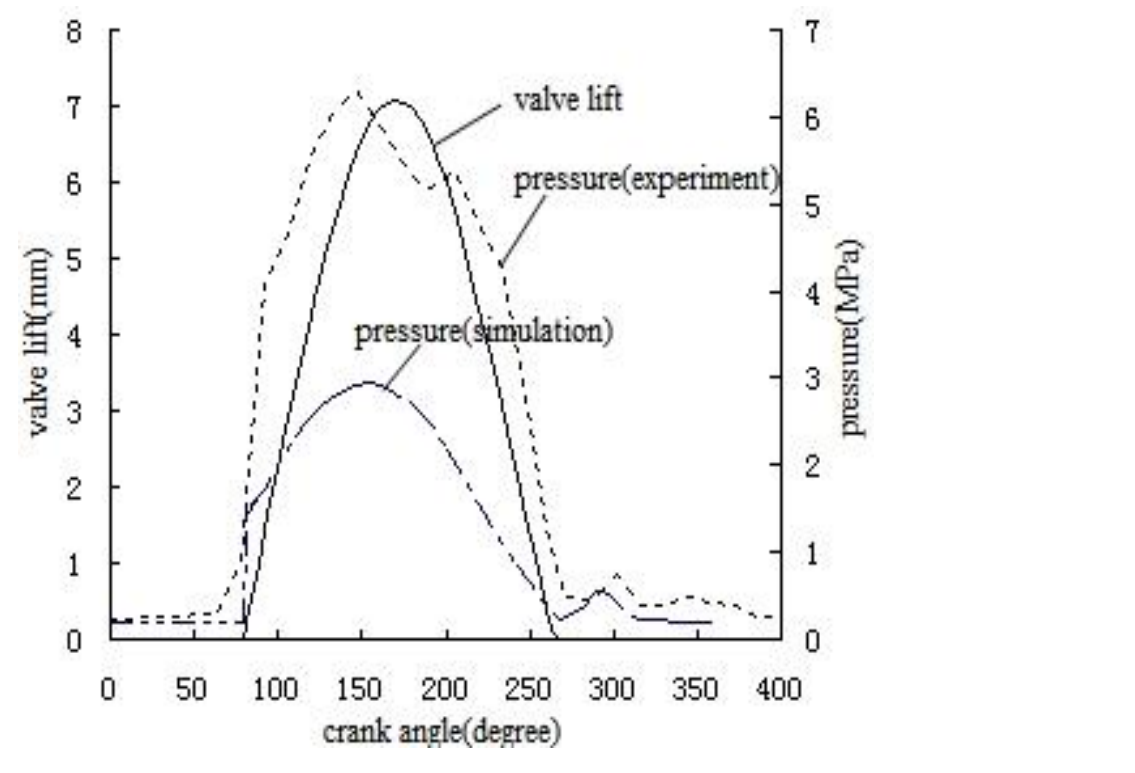

Figure 9. The Pressure Curve of Valve Cylinder at $800 \mathrm{r} / \mathrm{min}$

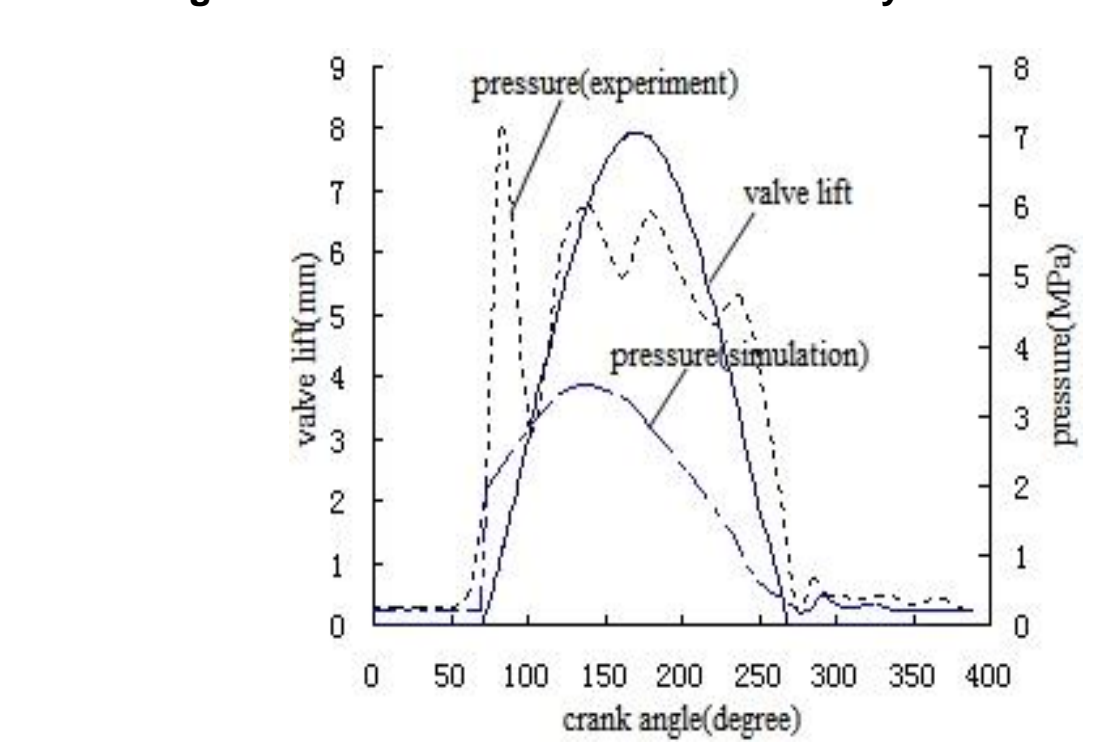

Figure 10. The Pressure Curve of Valve Cylinder at $1500 \mathrm{r} / \mathrm{min}$ 


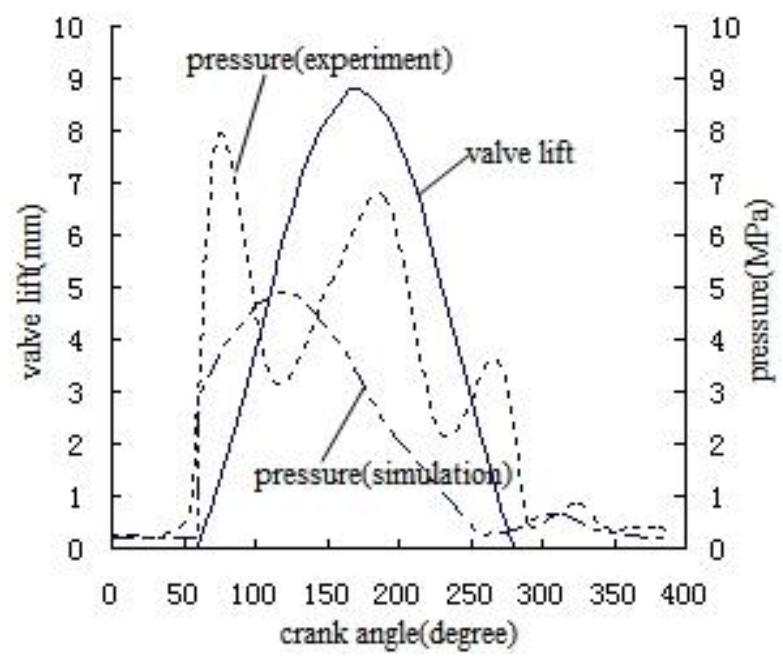

Figure 11. The Pressure Curve of Valve Cylinder at $3000 \mathrm{r} / \mathrm{min}$

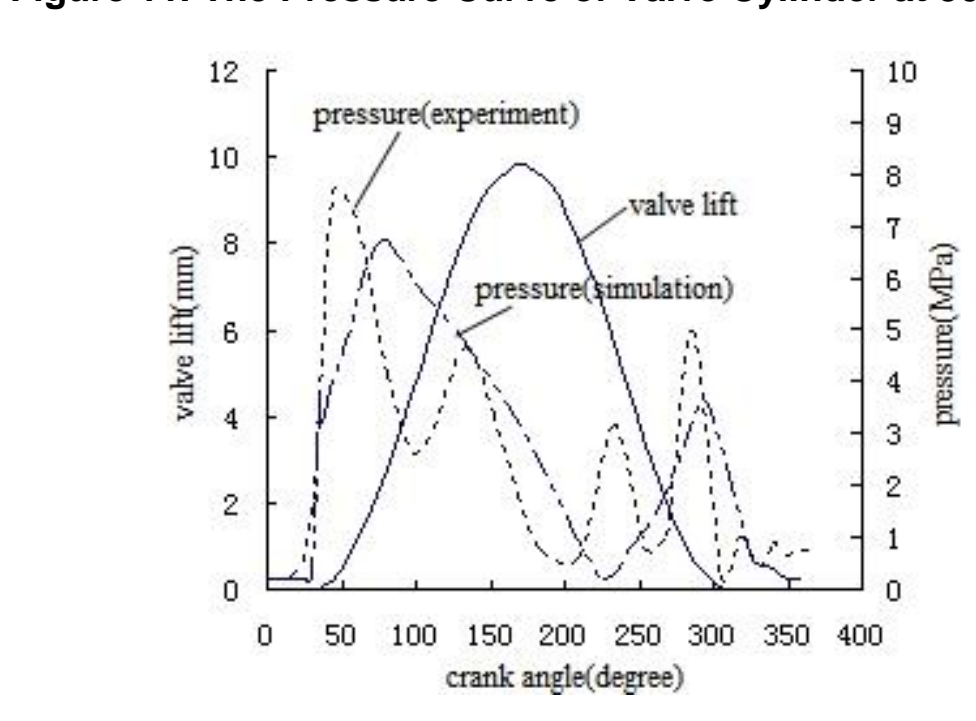

Figure 12. The Pressure Curve of Valve Cylinder at $6000 \mathrm{r} / \mathrm{min}$

Figure 9- Figure 12 show that although the trend of pressure curves of simulation and measured pressure curve in valve cylinder is very consistent, but there is a big error between them. There are several reasons to cause this situation [12]: Firstly, there are differences simulation model and the actual system, such as the pipes of system are considered to be ideal in the simulation model, but the pipes of system are not ideal in the test rig; the pressure of oil filling system is considered to be constant in the simulation model, but it is fluctuant in actual system. Secondly, there is error between the theoretical profile of cam and the actual profile of cam. Thirdly, some parameters are unreasonable, such as elastic modulus of hydraulic oil.

\section{Conclusion}

1) The best valve timing of engine is that both the advance angle, the lag angle, the duration angle, overlap angle of intake valve and exhaust valve should increase with the engine speed, and decrease with the engine speed decreases. 
2) The novel variable valve timing system can adjust the valve timing according to the operating condition of the engine in accordance with the best valve timing principle of the paper.

3) The valve cylinder pressure of novel variable valve timing system increases with the engine speed increases, the oil pressure fluctuation is intensified. The novel variable valve timing system allows maximum engine speed is $6000 \mathrm{r} / \mathrm{min}$.

\section{Nomenclature}

$\theta$ :crank angle ( degree )

$n$ :engine speed ( $\mathrm{r} / \mathrm{min})$

$t$ :time( second)

$A_{1}$ : cross-section area of the cam cylinder piston $\left(\mathrm{mm}^{2}\right)$

$A_{2}$ : cross-section area of the valve piston $\left(\mathrm{mm}^{2}\right)$

$x_{1}$ :displacement of the cam cylinder piston $(\mathrm{mm}$

$x_{2}$ : valve lift. ( $\mathrm{mm}$ )

$V_{1}$ : initial volume of cam cylinder $\left(\mathrm{mm}^{3}\right.$

$V_{2}$ : initial volume of valve cylinder $\left(\mathrm{mm}^{3}\right)$

$p_{1}$ : instantaneous pressure of cam cylinder( MPa)

$p_{2}$ :instantaneous pressure of valve cylinder( $(\mathrm{MPa})$

$p_{3}$ : pressure of supply oil line (MP)

$Q_{2}$ : volume flow of hydraulic from into the valve cylinder( $\mathrm{ml} / \mathrm{min}$ )

$Q_{3}$ :volume flow of Hydraulic flow into the system supplied by supply oil line( $\mathrm{ml} / \mathrm{min}$ )

$Q_{4}$ :volume flow of Hydrgalic flow into the tank by oil unload line $(\mathrm{ml} / \mathrm{min})$

$d$ : diameter of pipe connects the cam cylinder with valve cylinder $(\mathrm{mm})$

$l$ : length of pipe connects the cam cylinder with valve cylinder $(\mathrm{mm})$

$\mu$ : hydraulic oil viscosity $\left(\mathrm{mm}^{2} / \mathrm{s}\right)$

$\beta$ :hydraulic oil elastic modulus $\left(\mathrm{mm}^{2} / \mathrm{Pa}\right)$

$\alpha$ :crank turning angles as the solenoid valve from open to closed(degree )

$c$ :damping coefficient

$\rho$ :density of hydraulic medium $\left(\mathrm{kg} / \mathrm{m}^{3}\right)$

$C_{d}$ :discharge coefficient of valve orifice

$A_{c 1}$ :cross-section area of inlet check valve $\left(\mathrm{mm}^{2}\right)$

$A_{c 2}$ :cross-section area of electromagnetic valve $\left(\mathrm{mm}^{2}\right)$

$F_{2}$ :valve springs pre-tightening force $(\mathrm{N})$

$k_{2}$ :valve spring stiffness $(\mathrm{N} / \mathrm{mm})$ 


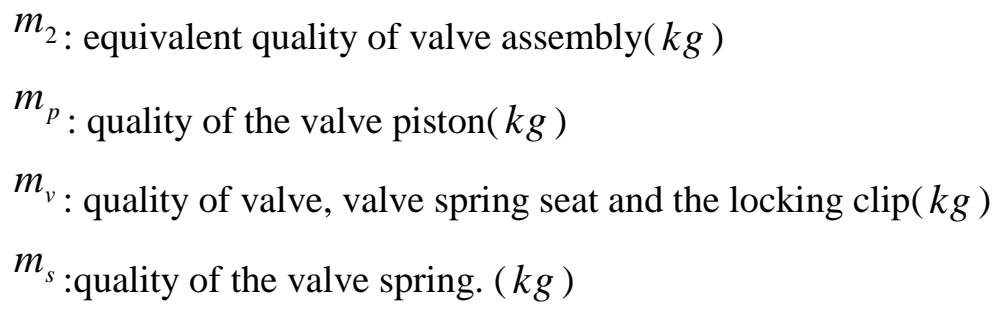

\section{References}

[1] S. Yan, L. Liguang, X. Min and Z. Chaoyang, "Foreign Research Progress of Engine Variable Valve Timing - Chapter Mechanism", Automobile Technology, vol. 6, (1999).

[2] T. M. Lancefield, R. J. Gayler and A. Chattopadhay, "The practical Application and Effects of a Variable Event Valve Timing System", SAE Paper 930825.

[3] T. Dresner, "A Review and Classification of Variable Valve Timing Mechanism", SAE Plaper 890674.

[4] P. Kreuter, P. Heuser, and M. Schebitz, "Strategies to Improve SF-Engine Performance by Means of Variable Intake Lift, Timing and Duration", SAE Paper 920449.

[5] R. Flierl and M. Kluting, "The Third Generation of Valvetrains-New Fuhy Variable Valvetrains for ThrottleFree Load Control", SAE Paper 2000011227.

[6] P. K. Wong and K. W. Mok, "Design and Modeling of a Novel Electremechanical Fully Variable Valve System”, SAE Papper 2008011733.

[7] L. Li, J. Tao, Y. Wang, Y. Su and M. Xiao, "Effects of Intake Valve Closing Timing on Gasoline Engine Performance and Emissions", SAE Papper 2001013564.

[8] BMW World, VANOS Variable Cam Timing [ EB /OI/, http://www. bmwworld.com / technology/vanos. html.

[9] W. Libiao, H. Bangquan and Xie Hui. "Study Progress of Éngine Variable Valve Technology", Automobile Technology, vol. 12, (2005).

[10] X. Kun, "The Principle of Aurmpbile Engine Tsinghua University press", BeiJing, (2010).

[11] W. Chunxing, "Hydraulic Contro System') China machine press, BeiJing, (2013).

[12] X. Zongfa, "Study on Fully Variable Hydraulid Valve System Drived by Valve - Train Cam", Shandong University Doctoral Dissertation, (2014).

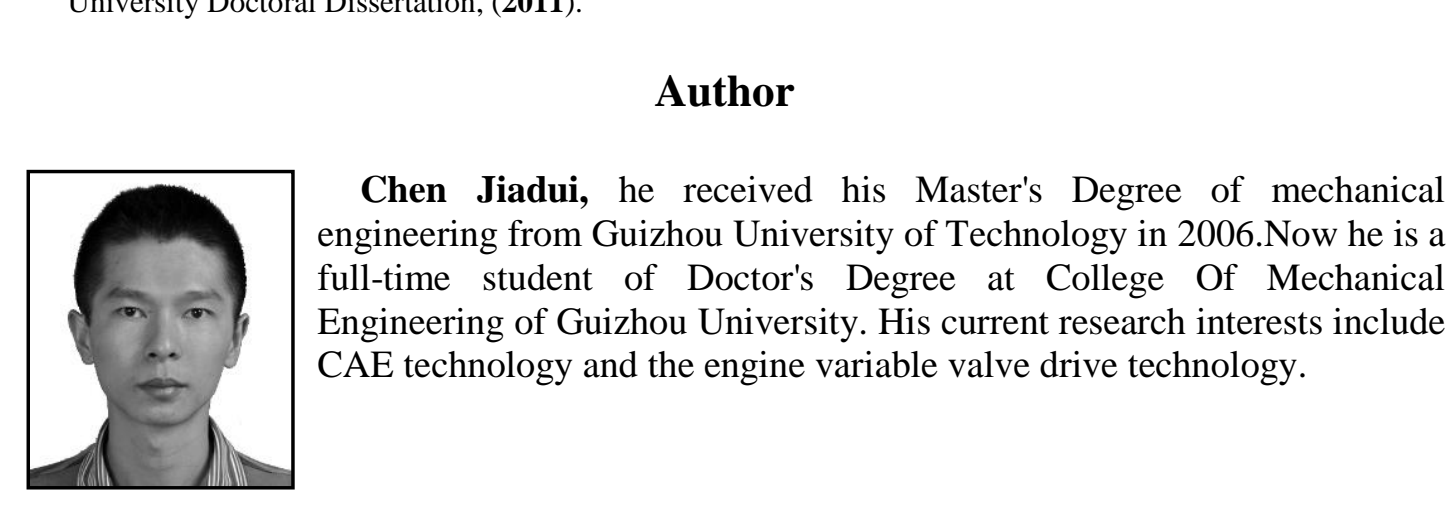

